\title{
RELAÇÃO ENTRE A ESTRUTURA, A ESTRATÉGIA E A ARQUITETURA ESTRATÉGICA COMO FATOR DE SUCESSO: UM ESTUDO DE CASO
}

\section{RELATIONSHIP BETWEEN STRUCTURE, STRATEGY AND STRATEGIC ARCHITECTURE AS A SUCCESS FACTOR: A STUDY CASE}

\author{
Ricardo Aurélio Quinhões Pinto, Mstd \\ Professor da Univille e Mestrando em Administração PUCPR \\ Departamento de Engenharia de Produção \\ ripi@terra.com.br \\ Mário César de Ramos, Mstd \\ Professor da Univille e Mestrando em Administração PUCPR \\ Departamento de Ciências Contábeis \\ mario_c_ramos@ig.com.br \\ Jansen Maia Del Corso, Dr. \\ Professor PUC-PR \\ Departamento de Administração \\ del.corso@pucpr.br
}

\begin{abstract}
RESUMO
Muitas organizações nascem e morrem todos os anos. Mais de $50 \%$ delas sequer completa 3 anos de existência. O objetivo deste estudo é entender como o gerenciamento estratégico de uma organização pode levá-la a sobreviver em um mercado extremamente exigente e competitivo, que costuma não perdoar os erros das pequenas empresas. A estratégia da empresa em estudo a levou a atingir a posição de liderança do seu segmento em apenas 10 anos após sua fundação. Será observado como o gerenciamento do desdobramento da arquitetura estratégica em um planejamento estratégico composto de um conjunto bem coordenado e flexível de práticas e procedimentos que permearam toda a
\end{abstract}


corporação, permitiu que a empresa mantivesse o passo de crescimento acelerado que a marcou até o momento. Apesar das limitações desta pesquisa, no que tange sua abrangência, as idéias básicas poderão ser extrapoladas para outras organizações, sem o risco de incorrer-se em erro teórico. O método de pesquisa adotado é o estudo de caso único, descritivo, com pesquisa estruturada; as conclusões são baseadas em análise qualitativa.

PALAVRAS-CHAVE: estratégia, planejamento estratégico, arquitetura estratégica, competências centrais e estrutura.

\begin{abstract}
Many organizations born and die every year. More than $50 \%$ of them don't even complete 3 year of existence. The subject of that study is to understand how the strategic management of a firm makes it not only a survivor but to rise to a leading position in its segment of the market, in just 10 years from its incorporation. This work will focus on how the management of the strategic architecture deployment unfolded into a mirrored structure composed of a well coordinated, flexible ensemble of procedures and practices that seamlessly permeated the whole corporate body, allowing for its continuous, accelerated growth. Nevertheless the limitations of this research, as regarding its span, the basics ideas may be used in other firms with no risk of incurring a theoretical mistake. The research method adopted is single structured and descriptive case study, based upon qualitative analysis.
\end{abstract}

KEY WORDS: strategy, strategic planning, strategic architecture, core competences and structure.

\title{
1. INTRODUÇÃO
}

Para manter a sua sustentabilidade, as organizações buscam ferramentas adequadas que possam minimizar os impactos ocasionados pelas mudanças e pela concorrência. Estas ferramentas devem auxiliar os administradores no planejamento, execução e controle de suas atividades. Entretanto, na era da informação em que vivemos escolher uma ferramenta que possa refletir a realidade da organização não é uma tarefa fácil. Se no passado tínhamos escassez de dados e informações, pode-se afirmar que atualmente temos excesso. E o que fazer para que uma organização mantenha-se "viva" em um mercado tão competitivo? Infelizmente não existe uma receita que possa ser 
aplicada de forma homogênea para todas as organizações. Por isso não será a ferramenta utilizada, mas a relação existente entre a estrutura, a estratégia e arquitetura estratégica que poderão maximizar as chances de sobrevivência. Isto pode inclusive melhorar o desempenho organizacional.

Foi realizada pelo SEBRAE (Serviço Brasileiro de Apoio as Micro e Pequenas Empresas) em Agosto de 2007, uma pesquisa com o tema: "Fatores condicionantes e taxa de mortalidade de empresas no Brasil". Esta pesquisa foi efetuada com informações do primeiro trimestre de 2007 de empresas de pequeno porte. Os resultados demonstram que dentre as novas empresas abertas no país, cerca de 470 mil de acordo com as Juntas Comerciais, muitas não conseguem sobreviver. Cerca de 50\% morrem com até dois anos de existência, 56,4\% morrem com até três anos e 59,9\% com até quatro anos de vida. Motivos diferentes causam o insucesso das empresas pesquisadas. Entretanto existe um percentual de novas organizações que ao utilizarem uma estrutura adequada, uma estratégia bem definida, uma arquitetura estratégica voltada ao negócio e com foco em suas competências centrais, podem ser utilizadas como exemplo de sucesso empresarial.

A empresa Viqua, fabricante de torneiras e registros em plástico de engenharia destinados a irrigação e ao uso doméstico, com dez anos de existência conseguiu ampla penetração no mercado brasileiro e alguma representatividade significativa no mercado de exportação, comercializando seus produtos para alguns países da América do Sul e da África. Líder de mercado no seu segmento, sendo que em uma linha de produtos encontra-se atualmente sem competidores. Caracteriza-se como uma empresa de pequeno porte. Sua estratégia é um dos fatores que ajudaram a garantir sua posição no mercado.

Cada empresa possui uma estrutura, que afeta e é afetada pela estratégia. Por isso é preciso efetuar uma arquitetura estratégica específica. Entretanto, identificar a relação existente entre estrutura, estratégia e arquitetura estratégica é uma atividade complexa. Isto porque o administrador deve não somente conhecer 
o negócio a que a empresa faz parte como também ter condições de identificar novas oportunidades, inclusive com capacidade de previsão mercadológica. $\mathrm{Na}$ ânsia de buscar novos negócios o administrador pode utilizar ferramentas inadequadas, ou ainda não utilizar adequadamente as competências centrais existentes na organização.

O objetivo deste artigo é analisar a relação existente entre a estrutura, a estratégia e a arquitetura estratégica da empresa Viqua, que sustentaram sua estratégia no desenvolvimento de suas competências centrais e a deram este posto de líder ao invés de ser somente mais um dado estatístico do SEBRAE. 


\section{FUNDAMENTAÇÃO TEÓRICA}

\subsection{RELAÇÕES ENTRE ESTRATÉGIA, ARQUITETURA ESTRATÉGICA E O PLANEJAMENTO ESTRATÉGICO}

Em uma análise rápida, por analogia, pode-se entender o quadro geral que estabelece as diferenças entre as três ferramentas. A estratégia determina a opção para onde seguir, a arquitetura estratégica fornece um mapa de grande escala do caminho a ser seguido e o planejamento estratégico fornece um mapa detalhado de como se chegar ao objetivo final. As definições e entendimentos de estratégia empresarial variam de acordo com a própria visão e enfoque postural do autor. A formulação da estratégia pode ser estabelecida para o mesmo negócio de maneiras diferentes, entretanto, deve ser coerente com o plano estratégico e ligado intimamente a uma escola do planejamento estratégico. Porém, de uma forma mais ampla, entende-se que a estratégia seja ela explícita ou implícita é vista em toda empresa como uma ferramenta para identificar e projetar valores e oportunidades de ganhos para os stakeholders. Estes valores e oportunidades devem fornecer possibilidades de sustentabilidade para a organização. $O$ estabelecimento de uma estratégia possibilita uma antecipação ao futuro. Sendo assim, se uma empresa consegue antecipar os acontecimentos pode fornecer elementos que permitam enfrentar as mudanças internas ou externas.

A visão clássica da escola do posicionamento baseada em Porter, Chandler e Ansoff é de que a estratégia é um meticuloso processo racional de cálculo, análise e modelagem, com o intuito de maximizar as vantagens competitivas. Por esta linha filosófica, tanto os ambientes internos quanto os externos podem ser conduzidos pelo planejamento estratégico. De acordo com Kaplan \& Norton (2004, p.38):

A literatura sobre estratégia apresenta diversidade incomum. Os acadêmicos e os profissionais adotam modelos muito diferentes sobre 
estratégia e nem mesmo concordam sobre sua definição. Embora seja possível definir mapas estratégicos e Balanced Scorecards para qualquer enfoque estratégico, baseamos nossa abordagem no modelo geral construído por Michael Porter, pioneiro e líder de destaque na área de estratégia. Porter argumenta que a estratégia consiste em selecionar um conjunto de atividades em que a organização será excelente criando a diferenciação sustentável no mercado. A diferenciação sustentável pode consistir em fornecer aos clientes mais valor do que os concorrentes ou em fornecer valor comparável, porém a um custo mais baixo do que os concorrentes. Segundo Porter, "A diferenciação decorre tanto da escolha das atividades, quanto da maneira como são executadas".

E como definir que caminhos seguir para a superação das adversidades e a criação de novos valores diferenciados que venham a permitir maximizar o lucro, garantindo o sucesso de uma organização? Porter (1991) estabelece que existem três condições essenciais definidas na literatura que explicam o sucesso de uma organização. Como primeira condição tem-se que a firma precisa desenvolver e implementar conscientemente um conjunto de metas e políticas funcionais que coletivamente definam sua posição no mercado. Como segunda condição tem-se que o conjunto de metas e políticas deve alinhar seus pontos fortes e seus pontos fracos com as oportunidades e ameaças do seu segmento industrial. Como terceira condição tem-se que a estratégia deve estar centrada na criação e na exploração das suas competências diferenciadas.

Porter vê estratégia como um conjunto de diversas situações. Uma situação refere-se à integração das atividades de todas as funções dos sistemas de produção. Outra situação é o alinhamento da empresa com o ambiente que é dinâmico. Nesta circunstância a empresa também precisa ser dinâmica para que possa identificar as tendências e usá-las como um diferencial estratégico que deve ser perseguido em uma estratégia empresarial. No entanto, para o desenvolvimento e sustentação das condições estabelecidas por Porter, é necessário um conjunto de fatores que possibilitem o cumprimento das metas e objetivos. Isto poderá permitir adequações da estratégia ao longo do percurso, para corresponder as variações ambientais, isto é, o planejamento estratégico. 
Mintzberg (2000) entende que o planejamento estratégico é um processo gerencial que estabelece um direcionamento a ser seguido pela organização, com o objetivo de se obter uma otimização na relação entre a sua realidade interna e o seu ambiente externo. O planejamento estratégico é uma ferramenta que auxilia a busca de respostas que a organização precisa para atuar em um contexto competitivo e de constantes mudanças. No quadro 1 apresentam-se os níveis diferentes de estratégia na visão de diversos autores.

\begin{tabular}{|c|c|}
\hline Autores & Níveis de estratégia \\
\hline $\begin{array}{l}\text { Hofer e Schendel } \\
(1978, \text { p.57) }\end{array}$ & $\begin{array}{l}\text { - Estratégia corporativa; } \\
\text { - Estratégia organizacional }\end{array}$ \\
\hline $\begin{array}{l}\text { Lorange e Vancil } \\
\qquad(1977, \text { p.12) }\end{array}$ & $\begin{array}{l}\text { - Estratégia corporativa: com atenção aos interesses da coalizão dominante; } \\
\text { - Estratégia da unidade de negócios (estratégia organizacional): com } \\
\text { objetivos para atender a unidade de negócios em específico, e são traçados } \\
\text { pela administração da corporação; } \\
\text { - Estratégia por atividades: com os objetivos definidos pela administração da } \\
\text { unidade de negócios. }\end{array}$ \\
\hline $\begin{array}{c}\text { Montgomery e } \\
\text { Porter (1998, } \\
\text { p.237) }\end{array}$ & $\begin{array}{l}\text { - Estratégia das unidades de negócio ou competitiva; } \\
\text { - Estratégia corporativa ou da totalidade do grupo empresarial. }\end{array}$ \\
\hline $\begin{array}{l}\text { Johnson e Scholes } \\
\quad(1999, \text { p.13) }\end{array}$ & $\begin{array}{l}\text { - Estratégia corporativa: trata da estratégia de toda a corporação; } \\
\text { - Estratégia da unidade de negócios: visualiza a estratégia competitiva de } \\
\text { uma de terminada unidade de negócios e é a própria operacionalização dos } \\
\text { elementos que compõem os recursos da firma, (funcionários, processos e } \\
\text { tecnologias), no sentido de compor esforços para atingir as metas e } \\
\text { objetivos traçados pelas estratégias da corporação e da unidade de } \\
\text { negócio; } \\
\text { - Estratégia operacional: está em um nível inferior à estratégia da unidade } \\
\text { de negócios. }\end{array}$ \\
\hline
\end{tabular}

Quadro 1 - Níveis diferentes de estratégia

Fonte: Adaptado de Hofer e Shendel (1978); Lorange e Vancial (1977); Montgomery e Porter (1998); Johnson e Scholes (1999).

Verifica-se no quadro 1 que os autores são unânimes em considerar que um dos níveis diferentes de estratégia que deve ser considerado em uma empresa é a estratégia corporativa. A estratégica corporativa poderá auxiliar a empresa a identificar possíveis divergências internas ou externas. Uma palavra chave neste nível de estratégia é a comunicação. Seja através de meios eletrônicos ou impressos todos devem saber o que, como e quais são os objetivos estratégicos da organização. Caso exista alguma falha neste processo de comunicação isto poderá afetar negativamente os resultados da organização. Sendo assim cada 
nível é essencial para o processo de planejamento empresarial. O nível corporativo terá como atribuição principal buscar subsídios para a formulação e implementação do planejamento estratégico. O nível da unidade de negócios pode ser responsável pelo planejamento tático da organização. O nível organizacional deverá auxiliar no planejamento operacional que afetará diretamente a administração da empresa. Neste nível encontra-se a maneira com a empresa lida com seus fornecedores, clientes, estoques entre outros. Na Figura 1 pode-se ter uma visão mais integrada do planejamento estratégico e sua participação no planejamento empresarial, que define todas as estratégias da organização.

\begin{tabular}{|l|l|}
\hline $\begin{array}{l}\text { Nível } \\
\text { corporativo }\end{array}$ & Planejamento Estratégico \\
\hline $\begin{array}{l}\text { Nível de unidade } \\
\text { de negócios }\end{array}$ & Planejamento Tático \\
\hline $\begin{array}{l}\text { Nível } \\
\text { operacional }\end{array}$ & Planejamento Operacional \\
\hline $\begin{array}{l}\text { Administração: } \\
\text { - dos estoques } \\
\text { - da produção } \\
\text { - etc. }\end{array}$ & Fornecedores \\
\hline
\end{tabular}

Figura 1 - Planejamento empresarial e seus desdobramentos Fonte: Adaptado de Tubino (1997)

O planejamento estratégico é uma formulação detalhada, com alto grau de complexidade, embebida na essência da estratégia empresarial e interconectada por grande multiplicidade de fatores e componentes internos e externos. Estes fatores e componentes muitas vezes oscilam independentemente da vontade da organização. É uma poderosa ferramenta que possibilita a alta administração 
orientar-se nas tomadas de decisões no melhor tempo e de acordo com o que foi previamente determinado em condições favoráveis (sem urgências) para atingir as metas e objetivos. Porém, por sua característica mais prática, requer um detalhamento das ações e uma grande exatidão, nos seus pormenores para permitir o desenvolvimento uno e coeso entre todos os setores da organização. Desta forma, o período de tempo a ser contemplado pelo planejamento não pode ser longo. Pois mesmo em condições de uma relativa estabilidade, fica muito difícil prever detalhadamente acontecimentos em um futuro muito distante. Conforme Prahalad e Hamel (2005, p.125):

\footnotetext{
É impossível criar um plano detalhado para uma busca competitiva de dez ou quinze anos. O planejamento pressupõe um grau de exatidão (que preços, que canais, onde buscar, que estratégia de merchandising, que características de produtos) impossível de se alcançar em um horizonte superior a dois ou três anos.
}

Sendo assim, entende-se que há a necessidade de uma concepção mais abrangente, menos detalhada, dos caminhos a seguir em um prazo mais longo. Precisa-se de um desenho onde se possam estabelecer formalmente as principais capacidades a serem construídas, porém, sem especificar claramente como fazêlo. A arquitetura estratégica pode clarificar este caminho, oferecendo uma visão geral e abrangente.

\subsection{ARQUITETURA ESTRATÉGICA}

Para Nadler e Tushmann (2000) a arquitetura estratégica é o "design organizacional" que corresponde ao emprego das funcionalidades, a aquisição de novas competências ou a migração das competências existentes e a configuração da interface com os clientes. Esta arquitetura estratégica deve ser responsável 
pela maneira que a empresa estrutura, coordena e administra o trabalho das pessoas em busca de objetivos estratégicos os quais devem estar alinhados com o planejamento estratégico. Sendo assim não fará sentido buscar novos mercados adequando a estrutura da organização se o objetivo estratégico não for este. Para construir uma arquitetura estratégica, a alta gerência precisa saber quais serão os novos benefícios ou funcionalidades oferecidos aos clientes na próxima década. Precisa ainda ter conhecimento de quais competências essenciais serão necessárias para criar esses benefícios. E acima de tudo como será a interface com o cliente permitindo que tenha acesso a estes novos benefícios de maneira eficaz.

Para Prahalad e Hamel (2005) uma arquitetura estratégica define o que é necessário fazer certo no momento atual para que se possam atingir os objetivos futuros da organização. Pode ser considerado o vínculo essencial entre o hoje e o amanhã, entre o curto e o longo prazo. Sendo assim a arquitetura estratégica é considerada um plano amplo onde as oportunidades serão visualizadas e apreciadas. Mostra à organização quais competências precisam ser desenvolvidas agora, ou ainda que novos clientes precisam ser entendidos e quais canais deveriam ser explorados para possuir um amanhã favorável ao seu desenvolvimento. 
No quadro 2 apresenta-se segundo Prahalad e Hamel (2005) o que uma arquitetura estratégica de uma organização deve possuir.

\begin{tabular}{|l|l|}
\hline Arquitetura Estratégica & \multicolumn{1}{c|}{ Descrição } \\
\hline Informação & $\begin{array}{l}\text { É preciso decidir quem deve se comunicar com quem, sobre o que, } \\
\text { com que freqüência e formas. }\end{array}$ \\
\hline Social & $\begin{array}{l}\text { É preciso especificar que comportamentos devem ser estimulados e } \\
\text { que tipo de pessoas devem se sentir à vontade trabalhando na } \\
\text { organização. }\end{array}$ \\
\hline Financeira & $\begin{array}{l}\text { É preciso ter um ponto de vista sobre o equilíbrio ideal entre as } \\
\text { dívidas e lucros, sobre como financiar aquisições e vendas, sobre os } \\
\text { critérios para alocações de capital entre outras atividades financeiras. }\end{array}$ \\
\hline Quadro 2- Arquitetura estratégica em uma organização \\
Fonte: Adaptado de Prahalad e Hamel (2005).
\end{tabular}

Para Chandler (1962) a estrutura organizacional acompanha a estratégia de desenvolvimento das empresas. Em outras palavras a estratégia que as empresas adotam pode influenciar suas estruturas (frameworks), que podem sofrer alterações previsíveis ao longo do tempo. Esta afirmação está baseada em um estudo empírico dos problemas organizacionais de quatro grandes empresas norte americanas. Entretanto, podem-se extrair desta pesquisa algumas informações relevantes que podem auxiliar outras empresas com problemas similares. Não se trata de uma utilização de tais informações no seu estado bruto, mas da adequação para a realidade da empresa.

Conforme Nadler e Tushman (2000, p.59) existem quatro lições principais sobre o desenho organizacional. Na primeira lição entende-se que o ambiente impulsiona a arquitetura estratégica da empresa, seja porque a empresa se antecipa, seja porque reage às mudanças no mercado. Como segunda lição enfatiza-se que a estratégia impulsiona a arquitetura organizacional. A terceira lição comenta-se que o relacionamento entre estratégia e desenho organizacional é recíproco. Ainda nesta lição é preciso verificar que a maneira como a empresa é organizada influencia seu foco e seus horizontes de tempo. Como quarta lição questiona-se como será possível projetar e administrar tanto a integração como a diferenciação. De acordo com Hrebiniak (2006, p.115) "a estratégia afeta a estrutura, ou alternativamente, a estrutura é importante para a execução da 


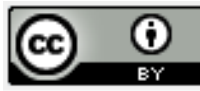

estratégia, tanto no nível corporativo quanto de negócios”. Hrebiniak (2006, p.140) tentando sintetizar o impacto da estratégia na estrutura descreve quatro impulsionadores estratégicos principais da escolha estrutural de uma organização que são demonstrados no quadro 3. Cada impulsionador estratégico poderá auxiliar de maneira convergente ao alcance dos resultados esperados. Entretanto se o impulsionador não estiver claro para os integrantes da organização poderá gerar informações inadequadas e interferir negativamente no desempenho organizacional.

\begin{tabular}{|l|l|}
\hline Impulsionadores & Descrição \\
\hline Tipo de estratégia & $\begin{array}{l}\text { A estrutura varia com a estratégia, quando, por exemplo, menciona que } \\
\text { para uma organização ter sua estratégia de atuação no mercado baseada } \\
\text { na liderança de custos, requer "certa confiança em uma estrutura } \\
\text { funcional (especialização em processo) por causa da sua capacidade de } \\
\text { reduzir os custos e obter várias economias". }\end{array}$ \\
\hline $\begin{array}{l}\text { Necessidade de } \\
\text { eficiência/eficácia }\end{array}$ & $\begin{array}{l}\text { A eficiência e a eficácia podem ser os objetivos traçados a fim de se obter } \\
\text { vantagens competitivas. Neste ponto o autor menciona que para se obter } \\
\text { eficiência deve-se ter uma estrutura administrativa centralizada e para se } \\
\text { obter eficácia deve-se descentralizar a estrutura. }\end{array}$ \\
\hline $\begin{array}{l}\text { Relação com } \\
\text { mercados e tecnologia }\end{array}$ & $\begin{array}{l}\text { O tipo e o grau da relação com o mercado são fatores importantes na } \\
\text { determinação estrutural. Um mesmo canal de distribuição pode atender a } \\
\text { diversos mercados, a mesmos clientes. Quanto maior for o grau de } \\
\text { relação dos mercados, maior será a probabilidade de centralização. }\end{array}$ \\
\hline $\begin{array}{l}\text { Crescimento e } \\
\text { tamanho } \\
\text { organizacional }\end{array}$ & $\begin{array}{l}\text { Empresas cujo tamanho gerem um alto grau de complexidade e } \\
\text { conseqüente dificuldades de coordenação, podem ter sua estrutura } \\
\text { descentralizada em unidades menores }\end{array}$ \\
\hline
\end{tabular}

Quadro 3 - Impulsionadores estratégicos principais

Fonte: Adaptado de Hrebiniak (2006)

O ambiente dinâmico com muitas mudanças impõe uma arquitetura estratégica que permita a evolução no caminho da competitividade. De acordo com Nadler e Tushman (2000, p. 59):

Hoje vemos o surgimento da empresa estratégica. O mercado mutante não premia o crescimento sem foco. Por isso, as empresas estão reformulando suas carteiras em busca do foco estratégico, concentrandose nos negócios que podem criar valor sustentável com a aplicação de suas competências básicas para proporcionar vantagem competitiva. 
No entanto, segundo Prahalad e Hamel (2005, p.143) "o objetivo de competir pelo futuro não é tanto estimular enormes riscos, mas sim trabalhar para tornar nossas ambições menos arriscadas." Desta forma, entende-se que o fato de as organizações posicionarem-se de forma antenada para o futuro, tentando aprender sobre ele de forma mais rápida que a concorrência, não deve significar a adoção de medidas que resultem em comprometimentos irreversíveis. A organização precisa ser flexível, ou seja, que possa adaptar-se aos constantes movimentos do mercado. Por outro lado, precisa criar uma estabilidade interna que possibilite tranqüilidade e certeza das suas ações. Com isso a sua arquitetura estratégica poderá gerar uma vantagem competitiva. $\mathrm{O}$ posicionamento adequado de mercado de uma organização pode estar relacionado à institucionalização de uma estratégia e uma arquitetura estratégica flexíveis. Esta flexibilidade e a constante evolução da organização podem direcioná-las na descoberta de suas competências centrais. As competências centrais de uma organização possibilitam bem mais do que simplesmente reagir a uma ameaça do mercado.

\subsection{COMPETÊNCIAS CENTRAIS - CORE COMPETENCES}

As competências centrais podem habilitar a empresa a antever as necessidades do mercado e mais do que isso, podem criar necessidades no próprio mercado, desenvolvendo nichos de consumos de seus produtos particulares. Conforme Prahalad e Hamel (1990, p.80) "o trabalho crítico do gerenciamento é criar uma organização capaz de infundir produtos com funcionalidade irresistível, ou, melhor ainda, criar produtos que os clientes precisem, mas que ainda nem imaginaram isso". Para Prahalad e Hamel (1990, p.81) "em curto prazo, a competitividade de uma organização deriva dos atributos da relação preço/performance dos seus produtos". Porém, é importante mencionar que o desenvolvimento dos processos de manufatura baseados na filosofia lean no oriente, que conseguiram de certa forma romper a relação de custo/benefício da curva trade off, hoje não são mais considerados uma grande barreira a novos entrantes no mercado e muito menos uma fonte vantagem competitiva. Estratégias ou ações estratégicas que sejam facilmente reproduzidas ou imitadas 
não podem ser consideradas como fontes de vantagem competitiva. Prahalad e Hamel (1990, p.81) comentam que:

\begin{abstract}
A verdadeira fonte de vantagem deve estar presente na habilidade de converter às vastas tecnologias corporativas e a destreza produtiva em competências que dão forças a unidade de negócios para uma rápida adequação as novas oportunidades.
\end{abstract}

De acordo com Paiva et al (2004, p. 76), "as competências da empresa são aquelas perceptíveis aos clientes e construídas a partir da combinação das competências de operações geradas a partir do uso criativo e inovador de seus diferentes recursos". Competências centrais são os aprendizados coletivos em uma organização, especialmente como se coordena diversas destrezas produtivas e integram diversas vertentes de tecnologia, é o envolvimento, a comunicação e o comprometimento para trabalhar através das fronteiras da organização. Conforme Prahalad e Hamel (1990, p.83) existem três testes que podem ser aplicados para identificar as competências centrais numa organização. O primeiro teste considera que uma competência central provê acesso a uma grande variedade de mercados. O segundo considera que uma competência central deverá ter uma significante contribuição aos benefícios percebidos pelo consumidor no produto final. $O$ terceiro teste considera que uma competência central deve ser de difícil imitação, ou seja, se esta competência for uma complexa harmonização de tecnologias individuais com a destreza produtiva.

Segundo Prahalad e Hamel (1990, p.84), existem casos em que a organização pode percorrer o caminho da perda de uma determinada competência que já possua. Um exemplo é quando uma empresa corta investimentos internos em favor de terceirizações como foi o caso da Chrysler. Outro exemplo é quando uma companhia desiste da oportunidade de estabelecer competências que estão envolvidas num negócio existente. Como foi o caso das empresas General Eletric, Motorola, GTE, Thorn e GEC que deixaram de produzir TVs por julgarem o produto maduro. Evidentemente, não devem ser identificadas as competências centrais apenas na função produção, mas também nas outras áreas. Assim, todas 
as competências funcionais deveriam convergir para um mesmo ponto estratégico, buscando atingir os objetivos da empresa, ou unidade de negócios. Para Prahalad e Hamel (2005, p. 257) "as empresas devem ser vistas como um portfólio de competências não mais como um portfólio de negócios".

\section{METODOLOGIA}

Este artigo tem por base um estudo de caso único em uma empresa de Joinville. Segundo Castro (2006, pág.31) "o objetivo da metodologia é o de ajudarnos a compreender, nos seus termos mais amplos, não os produtos da pesquisa, mas o próprio processo". Para Yin (2004, pág.32), um estudo de caso "é uma investigação empírica que: investiga um fenômeno contemporâneo dentro do seu contexto a vida real, especialmente quando os limites entre o fenômeno e o contexto não são claramente definidos”. De acordo com Malhotra (2006, pág.320) a "amostra é um subgrupo dos elementos da população selecionados para participação no estudo". A população deste estudo é representada pela empresa Viqua. A técnica de amostragem é não probabilística e por conveniência.

A Viqua possui planta industrial em Joinville, SC. Contando atualmente com 330 funcionários, tem como seu principal segmento de atuação a linha destinada a irrigação de agricultura (torneiras e conexões de PVC). Do seu total produzido, exporta aproximados $5 \%$ para os países do MERCOSUL, norte da América do Sul e Países do norte da África.

Segundo Yin (2004) o estudo de caso é a estratégia escolhida ao se examinarem acontecimentos contemporâneos, porém quando não se podem manipular comportamentos relevantes. Este método se utiliza de duas fontes de evidência: observação direta e série sistemática de entrevistas. De acordo com Roesch (1999), existem três características essenciais em um estudo de caso. A primeira característica é que o estudo de caso verifica fenômenos em profundidade dentro de seu contexto. A segunda é especialmente adequada ao 
estudo de processos organizacionais. Como terceira característica o estudo de caso explora fenômenos com base em vários ângulos.

O estudo de caso é mais uma, das muitas maneiras de se fazer pesquisa em Ciências Sociais. Porém, o estudo de caso comumente sofre muitos estereótipos, tais como: precisão (quantificação), objetividade e rigor insuficientes. Isto ocorre devido alguns fatores que de acordo com Yin (2004) são:

a) negligência;

b) não seguiram procedimentos sistemáticos;

c) aceite de evidências equivocadas;

d) visões tendenciosas;

e) confundiu-se o ensino de estudo de caso com o estudo de caso;

f) considerar que o estudo e caso fornece pouca base científica para fazer uma generalização científica;

g) e ainda considerar que o estudo de caso é muito demorado e gera muitos documentos ilegíveis.

A entrevista é uma das principais fontes de dados para estudos de caso. Segundo (Yin, 2004) a entrevista dentro do conceito da metodologia do estudo de caso pode ter várias configurações que são apresentadas no quadro 4.

\begin{tabular}{|c|l|}
\hline Entrevista & Descrição \\
\hline $\begin{array}{c}\text { Natureza Aberta- } \\
\text { Fechada }\end{array}$ & $\begin{array}{l}\text { Onde o investigador pode solicitar aos respondentes- chave a } \\
\text { apresentação de fatos e de suas opiniões a eles relacionados. }\end{array}$ \\
\hline Focada & $\begin{array}{l}\text { Onde o respondente é entrevistado por um curto período de tempo e } \\
\text { pode assumir um caráter aberto-fechado ou se tornar conversacional, } \\
\text { mas o investigador deve preferencialmente seguir as perguntas } \\
\text { estabelecidas no protocolo da pesquisa. }\end{array}$ \\
\hline Tipo Survey & Que implicam em questões e respostas mais estruturadas. \\
\hline
\end{tabular}
Quadro 4 - Configurações de entrevistas para estudo de caso Fonte: Adaptado de Yin (2004)

Yin (2004) considera que as entrevistas são fontes efetivas de evidências para o estudo de caso. Isto porque as entrevistas lidam com atividades de pessoas e grupos em pesquisa social. A questão a ser considerada neste tipo de metodologia é que as interpretações podem sofrer a influência dos observadores e 
entrevistadores. Sendo assim, podem ser reportadas de acordo com as idiossincrasias de quem faz e relata a entrevista. No entanto fica evidente que os entrevistados quando bem informados podem fornecer informações relevantes sobre atividades desenvolvidas. Desta forma, Yin frisa que o entrevistador deve atentar cuidadosamente para que os seus aspectos idiossincráticos não interfiram nos resultados da entrevista.

A pergunta principal a ser respondida neste artigo é: há relação entre estrutura, estratégia e arquitetura estratégica na Viqua? Este fato influenciou no seu desempenho?

\section{ANÁLISE DO CASO VIQUA}

O cumprimento de uma meta no alcance de um objetivo passa por um estudo em três níveis de escala: a estratégia, a arquitetura estratégica e o planejamento estratégico, que se desdobra em outros dois níveis: planejamento tático e planejamento operacional. As organizações de sucesso conseguem baseadas na sua estratégia, implementar todo um processo de planejamento. Este processo de planejamento tem início na concepção estratégica e termina em suas operações produtivas e logísticas. São desenvolvidas métricas que possibilitem a constante aferição entre as variações existentes entre os valores planejados e realizados. Estas variações positivas ou negativas fornecem elementos para as correções de percurso e adequações a estas novas realidades quando necessário.

A estrutura empresarial da Viqua foi estabelecida pelo planejamento estratégico. A empresa constituiu uma dinâmica de adequação de sua estrutura a sua realidade estratégica. Ela faz do planejamento estratégico o grande momento de materializar a visão, os objetivos e os projetos que nortearão a companhia nos próximos meses ou anos. Mantém uma rotina de elaboração do planejamento anual nos últimos meses do ano definindo os itens citados acima e toda a estrutura material e pessoal para suportar os objetivos e projetos propostos. Este 
planejamento estratégico é revisto a cada três meses e readequado de acordo com possíveis mudanças do ambiente que ocorreram neste período. Sendo assim, qualquer mudança significativa na estrutura empresarial será reavaliada dentro do planejamento estratégico. Existe um comitê de gestão do planejamento estratégico, composto por gerentes e diretores, que é responsável pela elaboração e aprovação das mudanças

Existe uma forte conexão com a estratégia durante as mudanças estruturais. Qualquer mudança estrutural advém de uma mudança na estratégia do negócio e só ocorre com a avaliação a aprovação do comitê de gestão do planejamento estratégico. A mudança estrutural ocorre após a aprovação da mudança estratégica refletida na mudança do planejamento estratégico. Desta forma, a Viqua cumpre a primeira das três condições essenciais estabelecidas por Porter (1991) para a sobrevivência de uma organização.

Os elementos da estratégia impulsionam a escolha da estrutura. Para a Viqua a estrutura sempre é uma conseqüência dos objetivos estratégicos. Por exemplo, quando definido que seria estratégico ter produtos diferenciados em design, a contratação de um designer e a criação de uma estrutura de P\&D, com laboratórios, equipamentos e softwares se tornou uma necessidade para que fosse atingido este objetivo. Sempre partiram da visão, desdobrada em objetivos e por fim em projetos que definem a necessidade da estrutura. A procura pelo desenvolvimento de uma competência central, que pudesse diferenciar os produtos da Viqua influenciou no desenvolvimento estrutural.

O ambiente de competição com os concorrentes, a tecnologia, o momento macroeconômico da economia e o crescimento do mercado em que estão inseridos são os principais ambientes estudados para formulação da estratégia. Estas são as características ambientais que mais influenciam na elaboração da estratégia.

Os imperativos estratégicos foram traduzidos em arquitetura estratégica. Os objetivos estratégicos são todos desdobrados em projetos, mas alguns possuem maior relevância para o alcance da estratégia do que outros. No desenvolver do planejamento estratégico, estes objetivos acabam tomando maior atenção e 
recursos que outros não prioritários. Quando a equipe percebe que os recursos disponíveis são limitados e que não será possível realizar em sua plenitude todos os projetos, a empresa opta em priorizar aqueles considerados relevantes. A relevância refere-se especificamente aos projetos que podem melhorar 0 desempenho organizacional.

A Viqua tem uma adequadamente definida estratégia de aquisição de competências. A estratégia sempre busca oportunidades no mercado que podem ser atendidas com competências existentes na empresa. Segundo o CEO da empresa, entrar em um mercado consolidado sem uma estratégia de diferenciação seria um erro. Por isso que o processo de planejamento estratégico sempre é finalizado com a discussão de como serão adquiridas as competências necessárias à sua implementação. Existem basicamente três estratégias que poderia ser utilizadas para isso. Uma seria a formação de pessoas que já possui em seu quadro de funcionários. Outra poderia ser a contratação de novas pessoas que possuam tal competência. Ou ainda a contratação de consultoria especializada. Para cada uma destas estratégias o fator custo-benefício é levado em consideração.

A estratégia sempre está procurando oportunidades no mercado que possam ser atendidas com suas competências. As competências atuais estão focadas em sua capacidade de desenvolver novas soluções e distribuí-las de forma eficiente no mercado nacional, criando uma marca forte junto aos seus clientes. Isto significa que as competências técnica e de marketing centrais.

A Viqua promove o alinhamento dos seus pontos fortes e seus pontos fracos com as oportunidades e ameaças do seu segmento industrial, centralizando suas ações na criação e na exploração das suas competências diferenciadas. Finalizando as condições essenciais estabelecidas por Porter (1991) para a sobrevivência de uma organização.

A empresa adota uma postura de perseguição ao "ótimo" entendendo que as empresas vencedoras são as que conseguem reinventar o seu mercado. Um exemplo é a Gol Linhas Aéreas que deixou de entregar um serviço que não agregava valor. Deixou de fornecer as refeições quentes em viagens de curta 
distância. Com esta e com outras ações conseguiu popularizar o que antes era considerado um luxo. Isto porque das muitas pessoas que nunca tinham viajado de avião, após as medidas adotadas pela empresa tornaram-se clientes usuais. Outro exemplo é a Starbuks, que transformou o local de se tomar um café em um ponto de encontro das pessoas. Pode-se comentar ainda o exemplo da Google que transformou a forma de pesquisar informações na internet.

A empresa Viqua procura de forma constante transformar o mercado em que atua. Sendo que o importante é reinventar a proposta de valor entregue por nossos produtos e serviços. Um produto e serviço não com a visão de mais barato, ou mais bem feito, mas diferente. Esta discussão deve permear por todo o planejamento estratégico, deste a definição da visão da empresa. Na Viqua futuro é visto como o momento histórico onde é possível sonhar (visão) e onde é possível realizar este sonho de uma estratégia adequada (objetivos) e bem implementada (projetos).

\section{CONSIDERAÇÕES FINAIS}

A Viqua possui um posicionamento de mercado orientado para visão de eficácia, visando à participação de mercado, a satisfação do cliente, com uma estrutura divisional para "fazer as coisas certas".

Mesmo em face ao grande dinamismo do mercado, ela consegue adequar seu planejamento estratégico a arquitetura estratégica através de constantes análises de tendências com uma forte visão de futuro adequada ao presente. É um intricado meandro, de gestão delicada, que exige determinação e extrema coordenação de ações estratégicas e oportunas.

Pela complexidade existente nesta relação é que a empresa consegue estabelecer uma forte competência central de difícil imitação. A empresa procura superar obstáculos que surgem ao longo do tempo e que podem ser decorrentes 
de fatores internos ou externos. Porém, para que estes obstáculos sejam superados sem que haja prejuízo para a organização e para aqueles que dela dependem é necessário estar atento ao mercado. Este mercado mutante exige que a empresa constantemente busque novas oportunidades de negócio, demonstrando dinamismo estratégico, tão enaltecido nestes novos tempos de globalização.

Nota-se que as três condições essenciais definidas por Porter (1991) que explicam o sucesso de uma organização: (i) implementar conscientemente um conjunto de metas e políticas funcionais que coletivamente definam sua posição no mercado; (ii) o conjunto de metas e políticas deve alinhar seus pontos fortes e seus pontos fracos com as oportunidades e ameaças do seu segmento industrial e (iii) a estratégia deve estar centrada na criação e na exploração das suas competências diferenciadas, são plenamente atendidas pela Viqua.

Vê-se também uma clara resposta positiva as três questões elaboradas por Prahalad e Hamel (1990) para identificação de uma competência central, sejam: (i) a competência central que a Viqua desenvolveu possibilita o atendimento a uma grande variedade de mercados, fornecendo uma ampla linha de produtos baseados em uma mesma tecnologia distribuída em todo o Brasil e em alguns países do exterior; (ii) a competência central tem uma significante contribuição aos produtos finais; (iii) a competência central da Viqua é de difícil detalhamento, representando uma complexa e harmoniosa integração de destrezas.

O planejamento estratégico permitiu a concepção estrutural de uma empresa formatada para o novo. A constante procura por soluções e melhorias de usabilidade possibilitou a capacidade de desenvolver produtos absolutamente novos, como as torneiras para ambientes sofisticados produzidas em plástico de engenharia, com formas e padrões que dificilmente serão atingidas com o uso do metal. Este talvez seja o caminho na direção do que foi dito por Prahalad e Hamel (1990, p.80) "o trabalho crítico do gerenciamento é criar uma organização capaz de infundir produtos com funcionalidade irresistível, ou, melhor ainda, criar produtos que os clientes precisem, mas que ainda nem imaginaram isso." 
Outro fator importante na gestão atual é a velocidade de resposta as mudanças ambientais. Não somente ater-se a implementar as alterações estratégicas necessárias, mas fazê-lo de forma rápida. O sistema de gerenciamento funcional verticalizado fortemente articulado, estabelecido pela Viqua talvez neste ponto venha a contribuir para agilizar todo o processo de decisão das mudanças. Existe um claro planejamento das ações, direcionando e coordenando as atividades de adequação do planejamento estratégico para adequar-se ao dinamismo do mercado. Isto confere a empresa uma forte competência competitiva, possibilitando-a antecipar-se aos concorrentes.

O administrador tem por convicção que para manter a sustentabilidade da empresa são necessárias ações preventivas. O "apagar incêndio", ações corretivas emergenciais, atuações sem uma devida previsão, devem ser utilizadas o menos possível (não se devem confundir estas ações urgentes com estratégia dinâmica). É preciso então que as pessoas conheçam o negócio da empresa, pois todos com maior ou menor envolvimento devem entender como está sendo planejado o futuro da organização. Certamente, e não acontece de forma diferente na empresa foco deste artigo, as informações devem ser filtradas e endereçadas às pessoas e ou setores responsáveis pelo "fazer acontecer". Sendo assim se a empresa continuar com uma estrutura, uma estratégia e uma arquitetura estratégica adequada e utilizando suas competências pode ser possível manter ou ainda melhorar seu desempenho organizacional.

Uma sugestão para a ampliação deste trabalho seria uma pesquisa em outras empresas com até 15 anos de existência no mercado, com o objetivo de identificar sua representatividade e posição no segmento, bem como qual a relação da sua situação de mercado com sua estratégia. 


\section{REFERÊNCIAS BIBLIOGRAFICAS}

CASTRO, C. DE M. A prática da pesquisa. 2.ed. São Paulo: Pearson Prentice Hall, 2006.

CHANDLER, Alfred D. Jr. Strategy and Structure: Chapters in the History of the American Industry Enterprise. Cambridge -Massachusetts: M.I.T Press, 1962.

HOFER, Charles W; SCHENDEL, Dan. Strategy Formulation: Analytical Concepts. Saint Paul, Minnesota: West Publishing Co., 1978.

HREBINIAK, Lawrence. G. Fazendo a Estratégia Funcionar: o caminho para uma execução bem sucedida. Porto Alegre: Bookman, 2006.

JOHNSON, Gerry; SCHOLES, Kevan. Exploring Corporate Strategy: Text and Cases. 5th. ed. New York: Prentice-Hall, 1999.

KAPLAN, Robert S; NORTON, David P. Mapas Estratégicos: Convertendo Ativos Intangíveis em Resultados Tangíveis. Rio de Janeiro: Campus, 2004.

LORANGE, Peter; VANCIL, Richard F. Strategic Planning Systems. New Jersey: Prentice-Hall, 1977.

MALHOTRA, N. Pesquisa de marketing: uma orientação aplicada. Porto Alegre: Bookman, 2006.

MINTZBERG, H. Safari da Estratégia. Porto Alegre: Bookman, 2000.

MONTGOMERY, C. A.; PORTER, M. E. Estratégia: a busca da vantagem competitiva. Rio de Janeiro: Campus, 1998.

NADLER, D. A; TUSHMAN, M. L. A organização do futuro. HSM Management, Jan/ Fev 2000, ano 4, $18^{\text {a }}$ edição.

PAIVA, E. L.; CARVALHO JR., J. M.; FENSTERSEIFER, J. E. Estratégia de Produção e de Operações: Conceitos, Melhores Práticas e Visão de Futuro. Porto Alegre: Bookman, 2004. 192 p.

PORTER, Michael E. Towards a dynamic theory of strategy. Strategic Management Journal, vol 12, 95-117, Nov/Dez de 1991. 
PRAHALAD, C. K; HAMEL, G. The Core Competence of the Corporation. Harvard Business Review, maio-junho de 1990.

PRAHALAD, C. K; HAMEL, G. Competindo pelo Futuro. Rio de Janeiro: Elsevier, 2005.

ROESCH, S. M. A. Projetos de Estágio e Pesquisa em Administração. São Paulo: Atlas, 1999

SEBRAE e Fundação Universitária de Brasília - FUBRA. Fatores Condicionantes e Taxa de Mortalidade de Empresas no Brasil. Novembro de 2004. Consulta ao site: http://www.sebraemg.com.br/arquivos/informativos/relatorio_pesquisa_mort alidade_minas.pdf - em 02 de agosto de 2008.

TUBINO, Dalvio F. Manual de Planejamento e Controle da Produção. São Paulo, Atlas, 1997.

YIN. Robert K. Estudo de Caso - Planejamento e Métodos. 3a . ed. Porto Alegre: Bookmann, 2004. 